\title{
L'impalpable et protecteur brouillard de la mémoire
}

\section{Françoise Merllié}

\section{OpenEdition}

1 Journals

Édition électronique

URL : http://journals.openedition.org/ccs/2583

DOI : $10.4000 /$ ccs.2583

ISSN : 2558-782X

Éditeur :

Presses universitaires de Rennes, Association des lecteurs de Claude Simon

\section{Édition imprimée}

Date de publication : 30 septembre 2019

Pagination : 289-291

ISBN : 978-2-7535-7795-4

ISSN : 1774-9425

\section{Référence électronique}

Françoise Merllié, «L'impalpable et protecteur brouillard de la mémoire », Cahiers Claude Simon [En ligne], 14 | 2019, mis en ligne le 30 septembre 2020, consulté le 10 octobre 2020. URL : http:// journals.openedition.org/ccs/2583; DOI : https://doi.org/10.4000/ccs.2583 


\title{
L'IMPALPABLE ET PROTECTEUR BROUILLARD DE LA MÉMOIRE
}

\author{
Françoise MERLLIÉ
}

Mes relations avec l'œuvre de Claude Simon ont été prudentes et tardives, à cause, sans doute, d'un lointain lien de parenté avec lui, et d'une connaissance trop envahissante de l'univers qu'il évoque, des paysages aux membres de sa famille. Connaissance parasite faite de rumeurs entendues dans mon enfance, de chuchotis scandalisés de gens blessés de s'être reconnus dans les livres - ou d'avoir reconnu leurs morts - car, selon que ces histoires étaient perçues comme véridiques, déformées ou même fictives, on passait de l'indécence au mensonge éhonté. J'ai gardé longtemps, vigilante et sournoise, l'ombre d'un personnage cynique faisant flèche de tout bois aux dépens de son entourage.

Sans doute avais-je aussi un peu honte de ma propre curiosité, du jeu à deviner qui était qui et à suivre les métamorphoses de ces personnages polymorphes. Mais surtout, très tôt, dès les premières pages, j'ai eu l'évidence d'une œuvre écrasante, trop riche, trop complexe : un kaléidoscope géant où récits, personnages, temps et lieux ne cessent d'éclater et de se recomposer. Et peut-être cette difficulté était-elle la principale raison de mon éloignement, plus encore que le malaise de voir à l'œuvre un grand prédateur.

Et pourtant... notre parente commune - sa presque petite sœur, la fille de son oncle tuteur - est morte récemment, et durant le long trajet en train vers la maison de famille à Perpignan, pour l'enterrement, je renoue comme une évidence avec les livres si longtemps négligés mais emportés à tout hasard : Leçon de choses, L'Acacia. Je lis, avec avidité presque, toutes défenses abolies, acceptant de ne pas tout comprendre comme dans un texte en langue étrangère où, sous peine de dégoût, on ne peut s'arrêter pour chercher le sens de chaque mot inconnu, 
mais où il faut deviner, avancer en saisissant l'essentiel. Et mystérieusement, ce monde éloigné devient plus familier, on comprend de mieux en mieux, sensible à un jeu de répétitions, de correspondances, qui s'éclairent mutuellement.

Ainsi, pour entrer dans l'univers littéraire de Claude Simon, suffit-il parfois d'abdiquer, de se laisser porter par les longues phrases sinueuses, dans une sorte de plaisir musical... fluidité des leitmotivs, variations innombrables sur le même thème, rythme et sonorités de la langue, chargée, dans ses replis, d'une force sensuelle où se mêlent couleurs, saveurs, douceur ou âpre rugosité pour dire la cruauté et la beauté du monde.

Mais mon expérience la plus intense de l'œuvre - la première fois qu'elle me marque aussi durablement -, je la dois à une lecture publique et collective du Tramway, qui clôturait, il y a peu, une journée Claude Simon à Perpignan. J'étais chargée des toutes dernières pages. Durant les semaines précédentes, cette lecture avait été préparée par une immersion lente, une sorte d'imprégnation laissant les mots progressivement dégager leur force et leurs résonances : inévitables souvenirs personnels du Roussillon exsangue en fin d'été; échos des milliers de pages écrites auparavant par Claude Simon et qui venaient doucement s'éteindre sur ces dernières lignes; échos plus lointains encore de siècles de littérature, de religion, de civilisations anciennes qu'il portait en lui.

Au cours de la lecture publique (ce moment où le verbe se fait chair!), le texte s'est déployé de voix en voix. Quand arrive mon tour, je sens, au bout de quelques phrases, que le lecteur précédent s'est éloigné. Personne ne viendra me relayer. Je suis seule. C'est la fin.

C'est la fin du trajet, la fin de l'été. C'est la fin du livre, et c'est la fin de l'œuvre. C'est aussi la fin d'une vie. Le vieil écrivain est retourné aux impressions vives de son enfance, comme pour un adieu. Une fois encore, surgit le souvenir de la mère, cette fois morte, invisible dans son cercueil refermé, mais fantasmée comme si s'étaient condensées en une seule image hideuse les images antérieures de son visage lentement ravagé par la maladie. Était-il plus facile de se séparer d'elle en l'imaginant si repoussante? Et combien faudra-t-il de chair fraîche pour masquer cette vision de cauchemar : la mère devenue la figure même de la mort?

La douleur de l'enfant n'est pas exprimée. Seulement sa révolte contre les tentatives pour enjoliver la réalité : "Non! " Elle n'était sûrement pas "si belle au milieu de toutes ces fleurs! " L'insupportable expérience est filtrée, voilée et n’apparaît que de façon décalée. Pour seules larmes, la coulure des 
cierges autour du cercueil et, plus loin, l'obstinée goutte de résine qui inlassablement sourd du pin parasol. La fin longue et torturée de la mère reste ainsi en arrière-fond, liée à l'agonie de l'été dont l'enfant a su pourtant saisir les derniers dons : odeurs, saveurs des fruits éclatés, couleurs, surtout, du rose suave au pourpre, du jaune d'or au gris, en particulier celui de la poussière qui finit par recouvrir les différentes parties du jardin, évoquées dans un sobre et minutieux inventaire.

Mais cette description très concrète du déclin de la nature glisse insensiblement à une réalité sous-jacente, le destin mortel de l'homme, grâce à des expressions à double sens comme "poussière ", qui, certes, désigne celle de septembre mais rappelle aussi le sinistre " Tu es poussière... ", tandis que la métaphore du linceul évoque l'ensevelissement des humains. Mais " cendres ", surtout, est un mot-pivot car ces cendres, signe de deuil, de destruction, de crémation, sont aussi gage de conservation (telle Pompéi, demeurée presque intacte sous les cendres volcaniques). L' "impalpable couche de cendres » devient enfin "impalpable " "brouillard " pour mener au tout dernier mot, qui illumine rétrospectivement l'ensemble de l'œuvre, car il est une affirmation sereine de survie : " mémoire »... « l'impalpable et protecteur brouillard de la mémoire ». Une mémoire-brouillard qui voile, brouille ce qui a été vécu mais le préserve, diffus, vivant, actif dans les textes. Ces dernières pages du Tramway ont ainsi valeur de legs, indéfiniment transmissible, car au fil des pages, au fil des mots, la mémoire de l'écrivain est devenue la nôtre.

Membre actif et enthousiaste de l'ALCS, fine lectrice de l'auvre de Claude Simon, Françoise Merllié nous a quittés en février 2019. Les Cahiers ont voulu lui rendre hommage par la réédition de ce beau texte, initialement mis en ligne en 2016 sur le site de l'association dans la rubrique "La première fois... ou pas ", ouverte aux lecteurs désireux d'évoquer leurs premières expériences de lecture de l'ouvre de Claude Simon [http://associationclaudesimon.org/lecteurs/la-premiere-fois-ou-pas/]. 